\title{
Pethidine in Low Doses versus Dipyrone for Pain Relief in Labor: A Randomized Controlled Trial
}

\section{Petidina em doses baixas versus dipirona para alívio da dor no trabalho de parto: um ensaio clínico randomizado}

\author{
Rogevando Rodrigues Nunes ${ }^{1}$ André Montenegro Primo ${ }^{1}$ \\ ${ }^{1}$ Graduate Program in Medical Sciences, Universidade de Fortaleza, \\ Fortaleza, CE, Brazil \\ Rev Bras Ginecol Obstet 2019;41:84-89. \\ Address for correspondence Rogevando Rodrigues Nunes, Master, \\ Programa de Graduação em Ciências Médicas, Universidade de \\ Fortaleza, Av. Washington Soares, 1321, 60811-905, Fortaleza, CE, \\ Brazil (e-mail: rogevando@hotmail.com).
}

\begin{abstract}
Objective To compare low doses of pethidine with dipyrone in labor analgesia. Methods In a randomized prospective study conducted by Universidade de Fortaleza, in the state of Ceará, Brazil, between May and December 2016, 200 full-term parturients, with very painful uterine contractions and exhibiting uterine cervix dilatation $\geq 5 \mathrm{~cm}$, were selected to receive a single intravenous dose of either $0.25 \mathrm{mg} / \mathrm{kg}$ of pethidine $(n=100)$ or of $25 \mathrm{mg} / \mathrm{kg}$ of dipyrone $(n=100)$. Pain was assessed using the visual analogue scale. The data were analyzed using the Student $t$-test, the chi-square test and the likelihood ratio.

Results There was a significant improvement in pain in 35\% of the parturients. Both drugs presented a similar analgesic effect 1 hour after the intervention $(p=0.692)$.

\section{Keywords}

- analgesia

- labor

- dipyrone

- pethidine

- humanizing delivery

\section{Resumo}
Palavras-chave
- analgesia
- trabalho de parto
- dipirona
- petidina
- parto humanizado There was no analgesic effect during the evaluation of the second hour after the intervention with pethidine or dipyrone. There were no adverse effects, such as maternal drowsiness, nausea or vomiting, related to the drugs used.

Conclusion Pethidine in low doses and dipyrone presented equivalent analgesia during labor.

Public Registry of Clinical Trials RBR-4hsyy4.

Objetivo Comparar doses baixas de petidina com dipirona na analgesia de parto. Métodos Em um estudo prospectivo randomizado realizado pela Universidade de Fortaleza, Ceará, Brasil, entre maio e dezembro de 2016, 200 parturientes a termo, com contrações uterinas muito dolorosas e apresentando dilatação do colo uterino $\geq 5 \mathrm{~cm}$, foram selecionadas para receber dose única intravenosa de 0,25 $\mathrm{mg} / \mathrm{kg}$ de petidina $(n=100)$ ou $25 \mathrm{mg} / \mathrm{kg}$ de dipirona $(n=100)$. A dor foi avaliada pela escala visual analógica. Os dados foram analisados por meio dos testes $t$ de Student, qui-quadrado e razão de verossimilhança.

Resultados Houve melhora significativa da dor em $35 \%$ das parturientes. Ambas as drogas apresentaram efeito analgésico semelhante 1 hora após a intervenção
\end{abstract}

(1DRogevando Rodrigues Nunes's ORCID is http://orcid.org/00000002-6025-1480.

received

August 3, 2018

accepted

October 22, 2018
DOI https://doi.org/

10.1055/s-0038-1676509. ISSN 0100-7203.
Copyright $\odot 2019$ by Thieme Revinter Publicações Ltda, Rio de Janeiro, Brazil
License terms

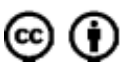


$(p=0.692)$. Inexistiu efeito analgésico durante a avaliação da segunda hora após a intervenção com a petidina ou com a dipirona. Não houve efeitos adversos, como sonolência, náuseas ou vômitos maternos, relacionados aos medicamentos utilizados. Conclusão A petidina em doses baixas e a dipirona apresentaram analgesia equivalente durante o trabalho de parto.

Registro público de testes clínicos RBR-4hsyy4.

\section{Introduction}

Pain control has always been a major concern of mankind, although it is often neglected and trivialized. In ancient times (prior to 476 A.D.), pain was believed to be a form of punishment from the gods or the demons.

Throughout the twentieth century, several drugs such as aspirin, pethidine, dipyrone, opium and ergotamine began to be employed to control pain. After that, more and more powerful analgesics began to emerge. ${ }^{1}$

Women often describe labor pain as the most intense painful sensation they have ever experienced. When the pain is very strong, it can lead to psychological trauma and, in some cases, negatively interfere with the normal course of labor. ${ }^{2}$ Posttraumatic stress disorder is a condition that is observed in 1 to $2 \%$ of postpartum patients. ${ }^{3}$

The high rates of cesarean births practiced in Brazil in recent years reach $55.6 \%$, contrasting with the $15 \%$ recommended by the World Health Organization (WHO). ${ }^{4}$ These high percentages reflect factors such as the phobia pregnant women feel regarding the pain of labor.

These factors determine a great need to find ways to relieve pain in these women.

Continuous epidural, which is used since 1947, is currently considered the gold standard in labor analgesia. ${ }^{5}$ However, it requires relevant additional financial resources, which hampers its use on a large scale. In countries where health investments are relatively scarce, such as Brazil, less costly analgesic options are required.

Pethidine has been used in labor since 1940. Well-documented studies employing dipyrone for this purpose have not been conducted. Both drugs are relatively inexpensive, easy to handle and safe, when used sparingly. Doses of up to $50 \mathrm{mg}$ of intravenous (IV) or intramuscular(IM) pethidine do not cause relevant changes in maternal-fetal vitality. ${ }^{6-11}$

Most studies found in the literature employ fixed doses of IV or IM pethidine ranging from $25 \mathrm{mg}$ to $100 \mathrm{mg}$ during labor. $^{12-16}$ After a search performed within the Capes, PubMed/Medline and BVS databases, from January 1st, 2000, to February 9th, 2016, we did not identify published research articles using doses of up to $50 \mathrm{mg}$ of IV pethidine during labor in which the dosages were individualized according to the body mass of the parturients.

Individual body mass may exert a strong influence on the effect of a given drug. In view of the inconvenience of routinely obtaining the blood concentration of drugs, it is more practical to administer them taking into consideration the individual body mass.
During pharmacological analgesia, it is necessary to administer an adequate dosage of the drug so that the pregnant woman does not manifest unwanted effects, and to maintain the vitality of the newborns.

This study compared the effects of pethidine (at low doses) and sodium dipyrone, when used in labor analgesia. Moreover, the Apgar scores were analyzed in the first and fifth minutes of life of the newborns, as well as the percentage of newborns who needed supplemental oxygen for a period $>30$ minutes during the first hour of life.

\section{Methods}

We conducted a controlled clinical trial. The study protocol was previously approved by Ethics in Research Committee of Universidade de Fortaleza (under CAAE 53754015.0.0000.5052). Informed consent was obtained previously from all of the parturients in the study.

Recruitment of the study sample took place through the distribution of posters at the hospital where the research was performed. A controlled, double-blinded trial randomized in 20 blocks was conducted. The research took place in Hospital Nossa Senhora da Conceição (HNSC), which is part of the hospital structure of the city of Fortaleza, in the state of Ceará, Brazil. The mentioned hospital does not have a labor analgesia service. The research was performed from May to December 2016.

The sample population ( $\mathrm{n}$ ) was defined using the variance, the significance, the minimum difference between the mean scores attributed to pain that could be identified in both groups, and the statistical power described in previous similar studies. ${ }^{17,18}$ The study power was of $90 \%$, with a significance of $5 \%(\alpha=0.05, \beta=0.1)$.

The present study recruited 200 parturients, and half ( $n=100$ ) of them were given $0.25 \mathrm{mg} / \mathrm{kg}$ of pethidine IV, and the other half $(n=100)$ were given $25 \mathrm{mg} / \mathrm{kg}$ of dipyrone $\mathrm{IV}$, in a single dose. The drugs were diluted in $18 \mathrm{ml}$ of distilled water and administered slowly, over the course of 5 minutes. The parturients received the analgesic as soon as they met the criteria required for admissibility in the research. During the research, one assistant generated the sequence of interventions on the computer, another collaborator prepared the medications, and another assistant administered the painkiller. The researcher collected the data from each participant. Neither the researcher nor the participants knew which of the two drugs had been administered to whom. The data were analyzed using the Predictive Analytic Software for Windows (PASW, SPSS Inc., Chicago, Il, US), version 17. The unpaired 
Student $t$-test, the same test paired with Bonferroni correction, the chi-squared $\left(\mathrm{X}^{2}\right)$ test and the likelihood ratio, whenever appropriate, were used. The quantitative analysis was performed using the Student $t$-test. For the qualitative analysis, the likelihood ratio and the $\mathrm{X}^{2}$ test were used.

The pain levels were assessed using the visual analogue scale (VAS), which has been an internationally recognized method for this purpose since $1976 .{ }^{19}$ The VAS scores the pain from " 0 " to " 10 ," with " 0 " being the absence of pain and " 10 " being the worst pain the participant believes she can endure. The pain was measured just before the analgesics were applied, as well as 1 hour and 2 hours later. This measurement was performed 1 minute after the end of the last painful uterine contraction. The medication was administered only to the parturients who reported intense pain resulting from uterine activity, with scores of 8,9 or 10 on the VAS.

During the hospitalization, the study was explained to the parturients. They received information about the fact that they were volunteering for the study, the probable benefits of the medications over pain, and the possible side effects they might experience, such as nausea, vomiting, allergic reactions, pain due to the venous puncture etc.
The inclusion criteria, which were always concomitantly present, were: a) presence of $\geq 3$ uterine contractions lasting $\geq 50$ seconds every 10 minutes; b) parturients presenting a dilation of the uterine cervix $\geq 5 \mathrm{~cm} ; \mathrm{c}$ ) intense pain; d) gestational age $\geq 37$ weeks and $\leq 40$ weeks and 6 days; e) cephalic presentation of the fetuses.

The exclusion criteria were: a) parturients with any of the following events: poorly-controlled arterial hypertension (with hypertensive spikes), diabetes, restricted intrauterine growth and placental abruption; b) use of oxytocin in labor; c) previously diagnosed and untreated hypothyroidism; d) users of monoamine oxidase inhibitors; e) the birth occurring in less than 1 hour after the intervention; f) parturients with body mass $\geq 100 \mathrm{~kg}$; g) indication of cesarean delivery during admission; h) previously-diagnosed Addison disease; i) fetal heart rate $($ FHR $)<110 \mathrm{bpm}$ or $>160 \mathrm{bpm}$ upon admission; j) patients allergic to sodium dipyrone; $\mathrm{k}$ ) patients allergic to pethidine; l) chlorpromazine users; $\mathrm{m}$ ) phenobarbital users; n) phenytoin users; o) fetuses without vitality; p) twin pregnancy; q) drug addiction.

Initially, 254 parturients were selected. After the inclusion and exclusion criteria were applied, only 200
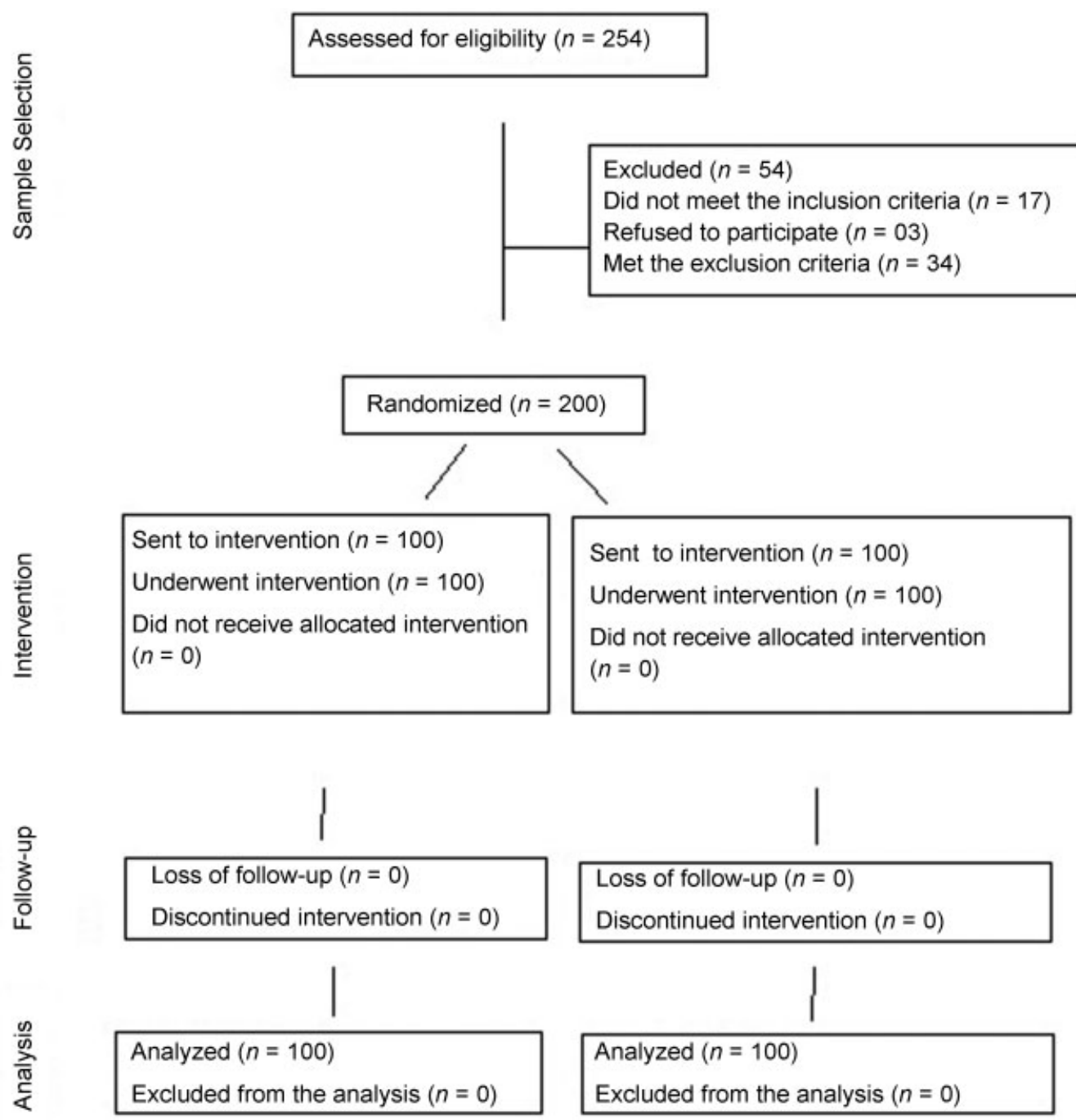

Fig. 1 Flow chart of the participants throughout the study. 
parturients met all of the requirements and became participants of the study (-Fig. 1).

\section{Results}

In the evaluation performed 1 hour after drug administration, an improvement in pain in the 2 groups was verified, benefiting $35 \%$ of the parturients. The primiparas represented $46.5 \%$ (93) of the sample; 44 of them used pethidine, and 49 used dipyrone. The mean age of the participants was 23.94 years for both groups, ranging from 14 to 44 years. During the assessment performed two hours after the intervention, no analgesic effect was described in the two groups. During the research, the drugs presented equivalent analgesic effects (-Table $\mathbf{1}$ ).

The Apgar scores at 1 and 5 minutes of life of the newborns did not show statistically significant differences during the comparison between the groups ( $\mathbf{- T a b l e ~} \mathbf{2}$ ).

The use of supplemental oxygen by the newborns over a period of more than 30 minutes during the first hour of life did not result in statistically significant differences between the groups (-Table $\mathbf{3}$ ).

There were no adverse effects, such as maternal drowsiness, nausea or vomiting, related to the drugs used.

\section{Discussion}

The pain relief obtained during the assessment performed 1 hour after analgesic administration was significant. The lowest score attributed to pain on the VAS was 7.97. The analgesia provided by both pethidine and dipyrone lost its effect after 2 hours. The Apgar score did not vary between the groups. The percentage of newborns that used supplemental oxygen for more than 30 minutes during the first hour of life was similar in both groups.

In a research using $50 \mathrm{mg}$ of pethidine IV, theVAS pain scores observed were of 6.6 and 7.3 respectively, at 1 hour and 2 hours after the administration of analgesics. ${ }^{8} \mathrm{~A}$ similar result was described in the study conducted by Khooshideh and Shahriari ${ }^{6} 1$ hour after the administration of $50 \mathrm{mg}$ of IM pethidine (VAS $=7$ ). These results are consistent with the present research, because, using a mean dose of IV pethidine of 16 to $20 \mathrm{mg}(0.25 \mathrm{mg} / \mathrm{kg})$ both the duration and the
Table 2 Apgar score for the newborns of mothers who underwent labor analgesia

\begin{tabular}{|l|l|l|l|}
\hline Variables & $\begin{array}{l}\text { Dipyrone } \\
(\boldsymbol{n}=\mathbf{1 0 0})\end{array}$ & $\begin{array}{l}\text { Pethidine } \\
(\boldsymbol{n}=\mathbf{1 0 0})\end{array}$ & -value $^{\mathrm{a}}$ \\
\hline $\begin{array}{l}\text { Apgar } \\
\mathbf{\text { minute }}\end{array}$ & $8.08 \pm 0.950$ & $8.09 \pm 0.570$ & 0.928 \\
\hline $\begin{array}{l}\text { Apgar } \\
5 \text { minutes }\end{array}$ & $8.90 \pm 0.541$ & $9.00 \pm 0.142$ & 0.077 \\
\hline
\end{tabular}

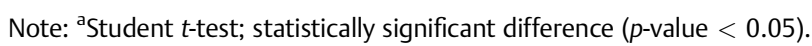

Table 3 Use of supplemental oxygen by the newborns of the parturients submitted to labor analgesia

\begin{tabular}{|c|c|c|c|}
\hline Variables & $\begin{array}{l}\text { Dipyrone } \\
(n=100)\end{array}$ & $\begin{array}{l}\text { Pethidine } \\
(n=100)\end{array}$ & $p$-value ${ }^{a}$ \\
\hline $\begin{array}{l}\text { Use of supplemental } \\
\text { oxygen for } \\
>30 \text { minutes } \\
\text { during the first } \\
\text { hour of life }\end{array}$ & $6(6 \%)$ & $9(9 \%)$ & 0.421 \\
\hline
\end{tabular}

Note: a Chi-squared test or likelihood ratio; statistically significant difference ( $p$-value $<0.05$ ).

intensity of the analgesia were lower than with the administration of $50 \mathrm{mg}$.

A study ${ }^{7}$ conducted in Egypt using 50 mg of IV pethidine, and another ${ }^{10}$ in Iran, which used $50 \mathrm{mg}$ of IM pethidine, did not observe differences in the Apgar scores at 1 and 5 minutes when compared with placebo.

A research ${ }^{20}$ published in Uruguay used $100 \mathrm{mg}$ of IV pethidine in the parturients and observed respiratory depression and acidosis in the newborns. Another study ${ }^{21}$ employed $100 \mathrm{mg}$ of IM pethidine every 3 hours during labor, and reported that $29.4 \%$ of the infants required nursery admission for special care.

The limitation of this study is due to the fact that the painful sensation related to labor assumes a magnitude related to the culture of each population. Due to this detail, the results found may not be reproducible in populations that are very different from our sample.

Table 1 Pain during the course of labor using the Visual Analogue Scale

\begin{tabular}{|l|l|l|l|}
\hline Time when the pain was evaluated & Dipyrone $(\boldsymbol{n}=100)$ & Pethidine $(\boldsymbol{n}=100)$ & $\boldsymbol{p}_{\text {-value }}{ }^{\mathrm{a}}$ \\
\hline Preanalgesia & $8.47 \pm 0.559$ & $8.55 \pm 0.626$ & 0.341 \\
\hline Preanalgesia/1 hour postanalgesia & $8.47 \pm 0.559 / 7.97 \pm 1.226$ & - & $<0.001^{\mathrm{b}}$ \\
\hline Preanalgesia/1 hour postanalgesia & - & $8.55 \pm 0.626 / 8.04 \pm 1.271$ & $<0.001^{\mathrm{b}}$ \\
\hline Preanalgesia/2 hours postanalgesia & $8.38 \pm 0.58 / 8.36 \pm 1.00$ & - & 0.908 \\
\hline Preanalgesia/2 hours postanalgesia & - & $8.44 \pm 0.56 / 8.52 \pm 1.04$ & 0.497 \\
\hline 1 hour postanalgesia & $7.97 \pm 1.226$ & $8.04 \pm 1.271$ & 0.692 \\
\hline 2 hour postanalgesia & $8.36 \pm 1.002$ & $8.52 \pm 1.039$ & 0.397 \\
\hline
\end{tabular}

Notes: ${ }^{\text {a }}$ Student $t$-test; ${ }^{b}$ statistically significant difference $(p$-value $<0.05)$. 
Some suggestions for the development of future researches involving these two drugs are pertinent, as follows:

1. Considering that the two analgesics have different mechanisms of action and cause significant effects in the first hour after administration, increases in the intensity of the analgesia and in the period of action, if the both drugs are used simultaneously, are expected.

2. Administration of only one of the two drugs. The doses would be increased to: the $35 \mathrm{mg} / \mathrm{kg}$ of dipyrone would be increased to up to $2.5 \mathrm{~g}$, and the $0.5 \mathrm{mg} / \mathrm{kg}$ of pethidine, up to $50 \mathrm{mg}$, to try to achieve a more intense and longer relief of the painful sensation. This would be a more adequate suggestion for intense pain, such as in cases of VAS scores of 8 .

3. Administration of the 2 drugs with increased dosages according to item 2, simultaneously, when the birth is expected to occur in the next 2 hours. The amount of benefited parturients should be greater than when employing merely one drug, and a more intense and longer lasting analgesia is presumed to occur. This option seems more appropriate for levels of intense pain, in which VAS $=9$ or 10 .

4. Administration of the 2 drugs, using increased dosages according to item 2, interspersed by 1.5 hour to 2 hours, if the initial prediction is for birth after 2 hours of the intervention. The intention is to achieve a longer-lasting, but less pronounced analgesic effect than the simultaneous administration of the drugs.

It is expected that, when labor analgesia becomes more accessible to the population, many women who are prone to having their child through surgery will opt for normal delivery. The health system itself would be favored by the reduction in cesarean sections, which would result in fewer infections and lower expenses, both on the part the state and on the part of the patients.

During labor, low doses of pethidine and dipyrone displayed similar analgesic effects measured at 1 hour after the IV administration of the drugs. However, the analgesic effect was not noticed during the evaluation conducted 2 hours after the intervention, regarding both drugs.

As for the newborns, no differences in the Apgar scores at 1 and 5 minutes were observed, and the use of supplemental oxygen for a period exceeding 30 minutes during the first hour postpartum was similar in both groups.

The current recommendation of the WHO is that the treatment of severe labor pain should be performed initially through non-pharmacological methods. The main non-pharmacological methods used in labor analgesia are: acupuncture, massages, ambulation, breathing exercises, shower baths, immersion baths, and cryotherapy (ice packs applied to the sacral region), as well as psychological methods such as audioanalgesia, hypnosis and presence of a companion for the patient in the delivery room. The pharmacological methods should be reserved if there is absence or ineffectiveness of the non-pharmacological methods. ${ }^{22-24}$

\section{Conclusion}

During labor, pethidine at low doses $(0.25 \mathrm{mg} / \mathrm{kg})$ and dipyrone at usual doses $(25 \mathrm{mg} / \mathrm{kg}$ ) presented equivalent analgesic effects 1 hour and 2 hours postintervention. The analgesic effect, however, lasted only during the first hour of evaluation for both drugs. The occurrence of adverse events for mothers and concepts was similar and indicative that both analgesia plans are safe during labor.

\section{Contributions}

The authors developed planned, collected the data, and analyzed the results of the present research. Author who conducted the research: RRN. Authors who analyzed the data: RRN; AMP. Authors who wrote the paper: RRN; AMP.

\section{Conflicts to Interest}

The authors have none to declare.

\section{Acknowledgments}

Universidade de Fortaleza (Unifor) contributed with guidelines and access to its library, and played an important role in the conception of the present work. The Health Department of the municipality of Fortaleza contributed with the necessary funding to carry out this work, and it deserves special thanks.

\section{References}

1 Jasiecka A, Maślanka T, Jaroszewski JJ. Pharmacological characteristics of metamizole. Pol J Vet Sci 2014;17(01):207-214. Doi: 10.2478/pjvs-2014-0030

2 Labor S, Maguire S. The pain of labour. Rev Pain 2008;2(02): 15-19. Doi: $10.1177 / 204946370800200205$

3 Stramrood CAI, Doornbos B, Wessel I, et al. Fathers with PTSD and depression in pregnancies complicated by preterm preeclampsia or PPROM. Arch Gynecol Obstet 2013;287(04):653-661. Doi: 10.1007/s00404-012-2611-0

4 Betrán AP, Ye J, Moller AB, Zhang J, Gülmezoglu AM, Torloni MR. The increasing trend in caesarean section rates: global, regional and national estimates: 1990-2014. PLoS One 2016;11(02): e0148343. Doi: 10.1371/journal.pone. 0148343

5 Reena KHB, Afzal M, Mishra AK, Paul A. Labor epidural analgesia: past, present and future. Indian J Pain 2014;28:71-81. Doi: 10.4103/0970-5333.132843

6 Khooshideh M, Shahriari A. A comparison of tramadol and pethidine analgesia on the duration of labour: a randomised clinical trial. Aust N Z J Obstet Gynaecol 2009;49(01):59-63. Doi: $10.1111 /$ j.1479-828X.2009.00949.x

7 El-Refaie TA, El-Said MM, Shoukry AA, Khafagy SM, El-Din AS, Badawy MM. Meperidine for uterine dystocia and its effect on duration of labor and neonatal acid-base status: a randomized clinical trial. J Obstet Gynaecol Res 2012;38(02):383-389. Doi: 10.1111/j.1447-0756.2011.01719.x

8 Elbohoty AEH, Abd-Elrazek H, Abd-El-Gawad M, Salama F, ElShorbagy M, Abd-El-Maeboud KHI. Intravenous infusion of paracetamol versus intravenous pethidine as an intrapartum analgesic in the first stage of labor. Int J Gynaecol Obstet 2012;118(01):7-10. Doi: 10.1016/j.ijgo.2012.01.025

9 Abdollahi MH, Mojibian M, Pishgahi A, et al. Intravenous paracetamol versus intramuscular pethidine in relief of labour pain in 
primigravid women. Niger Med J 2014;55(01):54-57. Doi: 10.4103/0300-1652.128167

10 Allameh Z, Tehrani HG, Ghasemi M. Comparing the impact of acupuncture and pethidine on reducing labor pain. Adv Biomed Res 2015;4:46. Doi: 10.4103/2277-9175.151302

11 Abu Dayyih W, El Tannir D, Mallah E, et al. Pethidine level in Jordanian women and their newborns during labor after a single intravenous dose. Int J Clin Anesthesiol 2014;2:1032

12 Tsui MHY, Ngan Kee WD, Ng FF, Lau TK. A double blinded randomised placebo-controlled study of intramuscular pethidine for pain relief in the first stage of labour. BJOG 2004;111(07): 648-655. Doi: 10.1111/j.1471-0528.2004.00160.x

13 Konefał H, Jaskot B, Czeszyńska MB. [Pethidine for labor analgesia; monitoring of newborn heart rate, blood pressure and oxygen saturation during the first 24 hours after the delivery]. Ginekol Pol 2012;83(05):357-362

14 Sekhavat L, Behdad S. The effects of meperidine analgesia during labor on fetal heart rate. Int J Biomed Sci 2009;5(01):59-62

15 Jain S, Arya VK, Gopalan S, Jain V. Analgesic efficacy of intramuscular opioids versus epidural analgesia in labor. Int J Gynaecol Obstet 2003;83(01):19-27. Doi: 10.1016/S0020-7292(03)00201-7

16 Smith LA, Burns E, Cuthbert A. Parenteral opioids for maternal pain management in labour. Cochrane Database Syst Rev 2018;6: CD007396

17 Douma MR, Verwey RA, Kam-Endtz CE, van der Linden PD, Stienstra R. Obstetric analgesia: a comparison of patient-con- trolled meperidine, remifentanil, and fentanyl in labour. $\mathrm{Br} \mathrm{J}$ Anaesth 2010;104(02):209-215. Doi: 10.1093/bja/aep359

18 Ng TKT, Cheng BCP, Chan WS, Lam KK, Chan MTV. A double-blind randomised comparison of intravenous patient-controlled remifentanil with intramuscular pethidine for labour analgesia. Anaesthesia 2011;66(09):796-801. Doi: 10.1111/j.1365-2044.2011. 06790.x

19 Serrano-Atero MS, Caballero J, Cañas A, García-Saura PL, SerranoÁlvarez C, Prieto J. Valoración del dolor. Rev Soc Esp Dolor 2002; 9:94-108

20 Sosa CG, Balaguer E, Alonso JG, Panizza R, Laborde A, Berrondo C. Meperidine for dystocia during the first stage of labor: A randomized controlled trial. Am J Obstet Gynecol 2004;191(04): 1212-1218. Doi: 10.1016/j.ajog.2004.03.017

21 Fleet J, Belan I, Jones MJ, Ullah S, Cyna AM. A comparison of fentanyl with pethidine for pain relief during childbirth: a randomised controlled trial. BJOG 2015;122(07):983-992. Doi: 10.1111/1471-0528.13249

22 World Health Organization. Maternal and Newborn Health/Safe Motherhood Unit. Care in normal birth: a practical guide. Geneva: WHO; 1996

23 Pandya ST. Labour analgesia: Recent advances. Indian J Anaesth 2010;54(05):400-408. Doi: 10.4103/0019-5049.71033

24 Hosseni SF, Pilevarzadeh M, Vazirinasab H. Non-pharmacological strategies on pain relief during labor. Biosci Biotechnol Res Asia 2016;13:701-706. Doi: 10.13005/bbra/2087 